\title{
La persuasión de la música en la publicidad. El ejemplo Coca-Cola
}

\author{
María-José SÁNCHEZ-PORRAS \\ Universidad de Granada \\ mjsporras@gmail.com
}

\section{Resumen}

En la actualidad, la publicidad en los medios audiovisuales está cambiando para poder seguir llegando a un mayor número de público. Esto se está haciendo a través del neuromarketing, jugando con el poder de la persuasión y de la música.

Palabras clave: Música; persuasión; neuromarketing; Coca-Cola; publicidad audiovisual.

\section{Music persuasion in audio-visual marketing. The example of Coca-Cola}

\begin{abstract}
Nowadays, marketing in audio-visual mass media is changing so that it can be available to the largest audience possible. This is possible through neuromarketing, playing with the power of persuasion and music.
\end{abstract}

Key Words: Music; persuasion; neuromarketing; Coca-Cola; audio-visual mass media.

\section{Referencia normalizada:}

Sánchez Porras, M. J. (2013) La persuasión de la música en la publicidad. El ejemplo Coca-Cola. Historia y Comunicación Social. Vol. 18. № Especial Diciembre. Págs. 349-357.

Sumario: 1. Introducción. 2. Metodología. 3. El poder de la persuasión a través de los spots. 3.1. La repercusión de la presencia de la música en los spots. 4. Análisis. 5. Conclusiones. 6. Referencias bibliográficas.

\section{Introducción}

Desde los principios de la humanidad la música se ha utilizado para expresar sentimientos, estados de ánimo, sucesos... por lo que ella misma se puede considerar como un medio de comunicación. A lo largo de la historia audiovisual, los profesionales de la comunicación han sido plenamente conscientes de que el sonido organizado constituía uno de los elementos más evocadores persuasivos del emergente lenguaje. La recurrencia a elementos del discurso sonoro para comunicar productos y servicios ha sido una constante. 
En la comunicación audiovisual actual parece imposible imaginar un mensaje sin música. ¿Qué espectador publicitario no conoce la canción de las muñecas de "Famosa" o del "Cola-Cao"? En este sentido, Guijarro y Muela (2003:57) apuntan: "en muchas ocasiones, hemos podido comprobar cómo la gente recuerda las melodías y las letras de anuncios que hace muchos años que no se han emitido". Y a pesar de que es ya bien conocido el potencial comunicativo de la música, sobre ella no hay un análisis y una reflexión que sean acordes a su relevancia.

Ante tal carencia sería necesario comenzar señalando que la música se ha considerado desde todos los tiempos como un arte, pero desde desiguales aspectos según la época, desde creer en su poder sobrenatural a pensar que puede afectar a la moral de las personas. La música es una compañera muy usual en la vida humana. Hay melodías que nos recuerdan momentos agradables, tristes, placenteros, y determinados productos de consumo. Todo el mundo hemos tarareado alguna vez una melodía perteneciente a un spot. Es este acto el que indica que se ha creado un vínculo con el consumidor que posiblemente le permite el recordar una marca.

Así, convergemos en el potencial que tiene la música en la publicidad. La apuesta por la banda sonora y más concretamente por la música como vehículo para expresar valores, atributos y experiencias emocionales es en el ámbito publicitario una apuesta segura. En unas ocasiones, nos invitará a cantar el mensaje, y el ritmo de la melodía condicionará la dicción del texto, actuando o no a favor de la estructura rítmica de cada palabra. En otras, comunicar un producto o un servicio a través de un lenguaje no verbal que acompañe a las palabras puede penetrar en el consumidor potencial de manera más subliminal y provocar un recuerdo mucho más duradero. En este sentido, la publicidad audiovisual se constituye como un lenguaje autorreferencial.

\section{Metodología}

Vamos a utilizar una metodología de carácter tanto cuantitativo como cualitativo, centrándonos en un análisis de contenido. Como orientación para nuestra investigación nos hemos apoyado en la base de datos para el estudio de la música en los anuncios de publicidad audiovisual de televisión realizada por Gómez Rodríguez (2005).

El campo de estudio que se abarca en este trabajo es de cincuenta spots de CocaCola encontrados en la red durante el año 2012.

Se va a estudiar concretamente los aspectos que a continuación se encuentran detallados:

- Percibir si lo que transmite un spot cambia con la presencia de la música.

- Estudiar qué finalidad tienen los estilos de música utilizados.

- Analizar el tipo mayoritario de música que se utiliza en los anuncios audiovisuales de Coca-Cola y si tiene la aprobación de la mayoría de los telespectadores. 
- Establecer si la música tiene relación con la acción del spot, si se utiliza una música incidental o diegética para conocer si llega al público de manera subjetiva sólo a través del oído o de forma objetiva, en la narración del anuncio.

- Estudiar en los spots si la música tiene una función de subrayado, apoyando la misma situación emocional que transfieren la voz hablada o las imágenes, estudiando las emociones que aporta la música en un spot.

Finalmente se analizará si cada vez que tenemos un silencio expresivo hay una parada en las imágenes, se llega a un clímax o hay una situación específica asociada siempre al silencio expresivo.

Los resultados obtenidos del análisis serán cuantitativos y cualitativos, a pesar de que el análisis se hará de forma cuantitativa, respondiendo cada spot a una serie de cuestiones cerradas.

\section{El poder de la persuasión a través de los spots}

En los inicios de la publicidad se buscaba la simbiosis entre el consumidor y el fabricante directamente. A comienzos de la década de los noventa el consumidor fue relacionándose ya con la marca, y el respeto por el fabricante fue sustituido por la confianza. En el transcurso de esta metamorfosis los elementos racionales fueron perdiendo poder y los elementos emocionales ocuparon el lugar de éstos en la toma de decisiones. Por eso se parte de que un spot ofrece al público más que una mera información comercial, proporciona un valor añadido (Gurrea, 1999:32).

En esta investigación se va a analizar en qué se fundamentó Coca- Cola para llegar a obtener una publicidad emocional, contemplando el lugar que ocupa la música en esta publicidad.

Debido a los últimos hallazgos médicos en las disciplinas neurocientíficas se ha descubierto que las emociones tienen un roll fundamental en la habitual toma de decisiones de la población en general. Es por ello que hoy en día la emoción no se considera un aspecto independiente del proceso mental.

Cuando una marca logra inducir en el cerebro del consumidor la emoción adecuada, éste puede llegar a ser fiel a tal marca, quedando afirmada una relación que se prolongará a través del tiempo. Y es aquí donde entra en juego el neuromarketing, ya que éste actúa en el cerebro del consumidor mediante la música, los colores, el sonido o la vista. Así, el telespectador recibe y asimila un determinado concepto, una estética concreta y en definitiva una experiencia cerebral que influye en el tacto, el oído, la vista y las emociones. 


\subsection{La repercusión de la presencia de la música en los spots}

La música se encuentra en una gran parte de los anuncios de televisión debido a su gran capacidad comunicativa. Puede estar presente en la publicidad de muy diversas formas, reproducir (o adaptar) canciones de la discografía universal o del mundo del cine, o ser compuesta expresamente para sugerir en un corto período de tiempo las emociones que quiere conseguir el spot. También puede estar presente a través de un jingle.

Algunos de los elementos con los que la música se distingue son la armonía, la melodía, el ritmo u otros igualmente sugerentes. Otra forma de hacerse destacar es permaneciendo en la memoria con que sólo uno de esos elementos sea pegadizo. Pero lo más relevante es que en la publicidad la música trata de provocar un estado de ánimo favorable y suscitar diversas emociones.

Varias disciplinas han estudiado las emociones que suscita la música, siempre analizando cada uno de sus elementos. En el siguiente ejemplo se presenta una interpretación de la función de diversos elementos musicales conforme a las emociones buscadas (Bruner Gordon, 1990). Se establece una conexión entre las expresiones emocionales y distintos elementos musicales, como son el modo, el tempo, el tono, el ritmo, la armonía y el volumen. Se obtiene como resultado que según la expresión emocional tenemos la siguiente correspondencia:

- Seria: mayor, lento, grave, firme, concordante y medio.

- Triste: menor, lento, grave, firme, discordante y bajo.

- Sentimental: menor, lento, medio, fluido, concordante y bajo.

- Serena: mayor, lento, medio, fluido, concordante y bajo.

- Cómica: mayor, rápido, agudo, fluido, concordante y medio.

- Alegre: mayor, rápido, agudo, fluido, concordante y medio.

- Emocionada: mayor, rápido, medio, irregular, discordante y alto.

- Majestuosa: mayor, medio, medio, firme, discordante y alto.

- Asustada: menor, lento, grave, irregular, discordante y variado.

En lo referente a las emociones que se emplea en la publicidad, como se puede comprobar, hay varias opciones, pero la ternura resulta más persuasiva con la marca y el mensaje (Aaker, Stayman \& Hagerty, 1986). Esto es debido a que este sentimiento sitúa al telespectador en un estado de ánimo positivo e incluso lo relaja.

La ternura puede suscitarse de muy diferentes formas, mediante historias o imágenes familiares, de amistad, protección, cariño o de amor entre animales o personas. O también, a través de escenas de tranquilidad y armonía entre la gente, la naturaleza y los animales. Igualmente, el humor y la música pueden suscitar una atmósfera de ternura para lograr que el spot sea más persuasivo. 
Paralelamente al estudio de las emociones, se plantea la cuestión de si el efecto de la música en las personas es intuitivo o aprendido, sobre lo cual no hay resolución clara. De hecho, en unas ocasiones puede ser automático mientras en otras es previamente asimilado. Por ejemplo, a menudo sonidos fuertes y repentinos asustan tanto a animales como a humanos recién nacidos, incluso si nunca antes los han oído; de otra parte, la música evoca sensaciones únicas debido a que algunas canciones están muy asociadas a determinados acontecimientos, historias y emociones. Incluso algunos estudios sostienen que uno debe "aprender" a apreciar la música y a asociarla con ciertos significados y emociones (Scott, 1990).

Para los publicistas, la interpretación cultural de la música tiene dos consecuencias. En primer lugar, ciertos spots pueden contener una obra musical acorde con su mensaje, mientras que los mismos anuncios deberían tener otra música dependiendo del tipo de cultura. En segundo lugar, la mima música no se comprende de la misma forma en las diferentes culturas, por lo que el ejemplo anteriormente expuesto, por ejemplo, se debería tener presente con cierta precaución en función de la cultura que se analice.

Dependiendo de cada ocasión, una obra musical nueva puede ser más favorable que otra ya conocida. Una pieza reconocible puede agradar y suscitar emociones enseguida, pero no necesariamente coincidirá con los propósitos del anunciante. Si se trata de una composición original posiblemente no suscite ningún recuerdo o afinidad inmediatamente, pero su estudiada repetición en una campaña alentará emociones intensas y con ello fidelidad hacia la marca.

\section{Análisis}

Analizando los cincuenta spots de Coca-Cola, se puede observar los principales resultados. Estos anuncios muestran diferentes expresiones emocionales mediante las cuales se aprecia la fuerza persuasiva que llega a tener la música en la publicidad audiovisual.

Analizaremos los puntos que consideramos más importantes para apreciar el poder de persuasión de la música en los anuncios audiovisuales de Coca-Cola. En primer lugar cabe destacar que la música está presente en el desarrollo del spot, esto ocurre en la mayor parte de los anuncios analizados (96,3\%); en ellos es empleada la música en algún momento.

Poniendo nuestra atención en la música de los anuncios audiovisuales, distinguimos si ésta es instrumental, vocal o mixta (vocal-instrumental). Más de un cuarto de los spots analizados utiliza música instrumental $(31,8 \%)$ y más de la mitad música mixta $(64,5 \%)$. No se ha encontrado ningún spot con música vocal a capella, lo que nos hace ver que la marca Coca-Cola prefiere que sus spots no tengan música $(3,7 \%)$ a que ésta sea vocal sin ningún tipo de acompañamiento instrumental (0,0\%). Sobre 
todo la música vocal- instrumental y en menor medida la música instrumental llegan más fácilmente al público, motivando un mayor grado de emoción por familiaridad.

En el total de los spots la música no sigue siempre el sistema tonal occidental, aunque sí la gran mayoría $(92,5 \%)$ frente a una pequeña parte $(7,5 \%)$ que no se rige por él. Partimos de que la cultura musical occidental se establece por este sistema determinado: el sistema tonal, con el cual se establecen unas relaciones asentadas culturalmente de antemano. Por eso nos sorprende que Coca-Cola utilice los mismos anuncios con la misma música para culturas muy distantes, como son la china y la europea.

Al analizar en los spots de Coca-Cola el tipo de música, nos encontramos con que una gran mayoría hace uso de la música popular-culta, de manera que ésta se utiliza en más de la mitad de los anuncios $(61,7 \%)$ frente a la música seria tonal $(18,7 \%)$ o la música popular $(9,3 \%)$. Además, una gran parte de estos anuncios $(79,9 \%)$ no contiene jingle frente a una pequeña cantidad $(18,7 \%)$ que sí goza de él. Se aprecia que Coca-Cola utiliza la música con el fin de que ésta sea conocida por el producto y no al contrario, pero también se establece una simbiosis: cuando la música llega más a los oyentes se convierte en un jingle popular fuera del ámbito del producto. Se logra así que, en cierto modo, producto y música sean asociados como si de uno sólo se tratara.

Al observar la función de la música dentro de los anuncios, es importante tener en cuenta que la música objetiva, al participar de forma real, es inseparable del resto del spot; por su parte, la música subjetiva crea un ambiente anímico que no podrían crear la imagen o la palabra solas. En la gran mayoría nuestra muestra la música es empleada en su función de música subjetiva $(94,4 \%)$, y esto nos muestra claramente que Coca-Cola, en su publicidad audiovisual, otorga una importancia primordial a la música.

Del mismo modo que se analizan las funciones parece interesante estudiar si existe una relación entre la participación de grupos instrumentales concretos y la pretensión de conseguir suscitar determinadas emociones o sentimientos en los anuncios de Coca-Cola. Nos encontramos con que la familia de los instrumentos aerófonos es la que menos presente está $(37,4 \%)$ seguida de los cordófonos $(46,7 \%)$, mientras que los instrumentos electrófonos ya están bastante más presente $(51,4 \%)$ y los instrumentos de la familia de percusión son los más utilizados $(76,6 \%)$ en el conjunto de los anuncios analizados. Por la reiteración de nuestra sociedad en general en escuchar música actual, la familia de los instrumentos de percusión y los electrófonos se encuentran más relacionados con los sentimientos alegres.

Un aspecto muy relevante para valorar es cómo se hace presente la música en los spots. Se aprecia que el carácter sobresaliente de la música atendiendo a su lugar de origen es incidental $(72,9 \%)$ frente a la diegética $(4,7 \%)$, aunque también en determinados casos se hace uso de ambas (18,7\%). Así, se demuestra que la música diegética no es muy utilizada en los spots de Coca-Cola. Esto es una prueba más de cómo se 
intenta que la música participe en el mensaje del spot por sí misma sin que el público tenga por qué ver los productores de ésta, sean instrumentos, voces o instrumentistas.

Uno de los últimos puntos a analizar es si la música expresa o no los mismos sentimientos que las imágenes en cada ocasión. En la casi totalidad de los anuncios es así $(94,4 \%)$, los sentimientos que expresa la música coinciden con los que transmite la imagen, y en una gran mayoría $(95,3 \%)$ la música participa de la acción del spot, es anímica. Con ello, se confirma que para acercar de una forma más inmediata el producto al público Coca-Cola se vale de la música en su publicidad audiovisual.

Finalmente, vemos cómo en un gran porcentaje de los spots analizados $(80,5 \%)$ no se hace uso del silencio expresivo mientras que en una pequeña cantidad $(19,5 \%)$ sí se utiliza. La marca no opta por emplear en sus anuncios este recurso, buscando que la fuerza persuasiva de la música sea mayormente la presencia de ésta ininterrumpida a lo largo de sus spots.

\section{Conclusiones}

A través de las conclusiones se va a mostrar qué hace que el arte de la música sea empleado en la publicidad como un elemento fuertemente persuasivo. Igualmente, se mostrará cómo su presencia se vuelve insustituible en el trascurso de los spots. La música es elemento básico para acercar más el consumidor al producto y viceversa.

Se hace evidente, en primer lugar, que Coca-Cola se apoya en la música para comunicar a través de su publicidad audiovisual diferentes mensajes. Podemos deducir que se busca una publicidad que llegue a la gran masa de la sociedad, independientemente del origen, el sexo o la edad de las personas. Para ello se selecciona debidamente tanto el género como el tipo de música utilizado.

A través de estos mensajes se transmite el valor central en torno al cual gira su publicidad: la felicidad. Se desarrolla para ello una comunicación universal a través de la transmisión de sentimientos como son alegría, emoción y bienestar. Todo esto se logra usando un lenguaje musical próximo a las personas, así como una cualidad tímbrica o un tipo de estructura familiar para oído del público.

Así, esta publicidad prioriza el conseguir fidelidad en sus consumidores, enfocando más de la mitad de sus anuncios al conjunto general de la población. Además, busca lograr otros consumidores nuevos, para lo que orienta un número significativo de spots a la población más joven. Con esto corroboramos una vez más cómo es el gran público el verdadero objetivo de estos spots.

La gran mayoría de los spots contiene música, sobre todo en la parte final, para grabar un mensaje en los telespectadores, ya sea acompañando la palabra Coca-Cola o bien junto a un eslogan escrito o hablado. Se emplea mayoritariamente la música vocal- instrumental, e incluso se aprecia que hay mayor uso del modelo canción para 
hacerlo más pegadizo al público y que de esta manera la melodía asociada al producto sea más fácil de interpretar.

Un punto importante del análisis es la presencia del jingle popularizado. Se aprecia que Coca-Cola inventa la música para su anuncio o recupera otra ya olvidada. Lo que sí se puede concluir es que la palabra Coca-Cola aparece en más de la mitad de los jingles, lo que permite que a la vez que se interioriza la melodía se recuerde el nombre del producto. Se produce un intercambio: el spot vende la música mientras ésta vende el producto. Visto de otra manera, se logra que los telespectadores se fijen en el producto y lo recuerden a través de la música. La música colabora a hacerles recordar el producto publicitado, graba en ellos el mensaje.

Con la música en todas sus funciones, apoyando y hasta potenciando el sentido de la imagen, se transmite al público una intencionalidad de que éste aprecie el producto y lo reconozca como agradable y cercano a él.

Con todo ello, concluimos que la marca Coca-Cola emplea la música en sus spots y con ella llega a su público consiguiendo que ni los anuncios ni el producto en sí pasen desapercibidos. No es en absoluto casual el modo de usar la música en esta publicidad, su presencia y uso son más que estudiados y el resultado tiene una importante repercusión en el comportamiento del telespectador.

\section{Referencia bibliográfica}

GUIJARRO, T.; MUELA, C. (2003). La música, la voz, los efectos y el sonido en publicidad. España: CIE Inversiones Editoriales Dossat 2000.

GURREA, Á. (1999). Los anuncios por dentro. Bilbao: Universidad del País Vasco. AAKER, D. and BRUZZONE, D. (1985). "Causes of Irritation in Advertising". In: Journal of Marketing, $n^{\circ}$ 49, EEUU: Spring, p. 47-57.

AAKER, D., SATAYMAN D., and HAGERTY, M. (1986). "Warmth in Advertising: Measurement, Impact and Sequence Effects". In: Journal of Consumer Research, $\mathrm{n}^{\mathrm{o}}$ 12, EEUU: March, p. 365-381.

BRUNER, G. II (1990). "Music and Marketing". In: Journal of Marketing, $\mathrm{n}^{\circ}$ 54, EEUU: October, p. 94-104, The subsequent definitions are adapted from this review of the literature on the topic.

GÓMEZ RODRÍGUEZ, J. A. (2005). ““"Lo que no se venda, cántelo”. Algunas reflexiones sobre el papel de la música en la publicidad: de los viejos pregones a los spots de televisión". En OLARTE MARTÍNEZ, M. (dir) (2001). La música en los medios audiovisuales. Salamanca: Plaza Universitaria Ediciones.

MILLIMAN, R. (1986). "The effect of Background Music on the Behavior of Restaurant Patrons". In: Journal of Consumer Research, $\mathrm{n}^{\mathrm{o}}$ 13, EEUU: September, $\mathrm{p}$. 286-289. 
SCOTT, L. (1990). "Understanding Jingles and Needle Drop: A Rhetorical Approach to Music in Advertising". In: Journal of Consumer Research, $\mathrm{n}^{\circ}$ 17, EEUU: September p. 223-236.

\section{La autora}

María José Sánchez Porras, natural de Córdoba, Profesora Superior de Música Especialidad de Solfeo Teoría de la Música, Transposición y Acompañamiento, Profesora de Música Especialidad de Piano, siendo funcionaria de carrera del Cuerpo de Profesores de Enseñanza Secundaria desde 2005. En el año 2007 obtuvo el Certificado-Diploma de Estudios Avanzados por la Universidad de Málaga dentro del Programa de Doctorado de Comunicación y Música. En la actualidad, realiza su tesis doctoral bajo la dirección de Doña Stella Martínez Rodrigo en la Universidad de Granada y se encuentra desempeñando su labor docente en el IES Nuevo Scala de Rute (Córdoba), donde actualmente tiene su plaza. 